\title{
STRATEGI KOMUNIKASI MEDIA SOSIAL UNTUK MENDORONG PARTISIPASI KHALAYAK PADA SITUS ONLINE KITABISA.COM
}

\author{
Social Media Communication Strategy to Encourage Participation of \\ Audience on Online Site Kitabisa.com \\ Herna $^{1}$, Hiswanti $^{2}$, Hidayaturahmi ${ }^{3}$, Amanda Anindya Putri $^{4}$ \\ ${ }^{1}$ Stikom ITKP \\ ${ }^{2}$ IBI Kosgoro 157 \\ ${ }^{3}$ STIA LAN Jakarta \\ ${ }^{4}$ Stikom ITKP \\ E-mail: herna_12140@yahoo.co.id, herna@itkp.ac.id
}

\begin{abstract}
The development and widespread use of internet technology has changed the way people communicate in everyday life. The most important indicator of this transformation is the emergence of new communication devices with internet technology called "digital communication devices" (Werbin 2012). Facebook, Twitter, Instagram, and similar social networks that are used online and virtual platforms such as web sites, microblogs, are new communication tools that are used as transformations of existing communication tools such as printed communication devices (journals, newspapers, etc. ), visual (television, cinema, etc.) and audio (radio) communication devices. The transformation is also followed by the way we donate, namely the transition from the offline system (directly giving to the mosque or orphanage) to the online donation system. One of the crowdfunding platforms (online donations) in Indonesia is Kitabisa.com. Lots of excess donations online, but the proliferation of online fraud makes the public (prospective donors) reluctant to participate in this program. So there needs to be a communication strategy between fund raisers and prospective donors to encourage public participation. This study used descriptive qualitative method. Techniques for collecting data with indepth observation interviews and document checking. The interview was conducted by interviewing the Kitabisa.com party as the party that built the donation and fundraising site for initiatives, campaigns and social programs that had the motto "Let's work together to build Indonesia!". Data analysis was performed using data analysis of Miles and Huberman. Message element theory in social media and participation theory is used in this study which discusses how message elements in a social media / donation site. To increase audience participation in fundraising through online sites, Kitabisa.com by uploading content that contains storytelling and video formats in each campaign that will be done on social media. Update campaigns, progress reports from each campaign, photos in the form of proof of activity are also regularly displayed on the website. This is done consistently to maintain the quality of the campaign and maintain public trust and participation.
\end{abstract}

Keywords: social media, message theory, online site Kitabisa.com

ABSTRAK
Perkembangan dan meluasnya penggunaan teknologi internet telah mengubah cara
masyarakat berkomunikasi dalam kehidupan sehari-hari. Indikator terpenting dari
transformasi ini adalah munculnya alat komunikasi baru dengan teknologi internet yang
disebut "digital alat komunikasi" (Werbin 2012). Facebook, Twitter, Instagram, dan
jejaring sosial serupa yang digunakan secara online dan platform virtual seperti web situs,
mikroblog, merupakan alat komunikasi baru yang digunakan sebagai transformasi dari
alat komunikasi yang sudah ada seperti alat komunikasi yang dicetak (jurnal, surat kabar,


dll.), visual (televisi, bioskop dll.) dan audio (radio) alat komunikasi.Transformasi tersebut juga diikuti oleh cara kita berdonasi yaitu peralihan dari sistem offline (secara langsung memberikan ke mesjid atau rumah yatim) ke sistem donasi online. Salah satu crowdfunding platform (donasi secara online) di Indonesia adalah Kitabisa.com. Banyak kelebihan donasi secara online, tetapi maraknya penipuan online membuat khalayak (calon donatur) enggan berpartisipasi dalam program ini. Sehingga perlu adanya strategi komunikasi antara penggalang dana dan calon donatur untuk mendorong partisipasi khalayak. Penelitian ini menggunakan metode deskriptif kualitatif. Teknik pengumpulan data dengan in-depth interview observasi dan pengecekan dokumen. Wawancara dilakukan dengan mewawancarai pihak kitabisa.com sebagai pihak yang membangun situs donasi dan menggalang dana (fundraising) untuk inisiatif, campaign dan program sosial yang memiliki motto "Mari bergotong royong membangun Indonesia!". Analisis data dilakukan dengan menggunakan analisis data Miles dan Huberman. Teori elemen pesan dalam sosial media dan teori partisipasi digunakan dalam penelitian ini yang membahas bagaimana elemen-elemen pesan dalam sebuah media sosial/situs donasi. Untuk meningkatkan partisipasi khalayak dalam penggalangan dana melalui situs online, Kitabisa.com dengan cara mengunggah konten yang berisi storytelling dan format video dalam setiap kampanye yang akan dilakukannya di media sosial. Update campaign, laporan perkembangan dari setiap kampanye, foto-foto yang berupa bukti kegiatan juga ditampilkan dalam website secara berkala. Hal tersebut dilakukan secara konsisten untuk menjaga kualitas campaign dan mempertahankan kepercayaan serta partisipasi khalayak.

Kata kunci: media sosial, teori pesan, situs online Kitabisa.com

\section{PENDAHULUAN}

Seiring perkembangan jaman, peran serta masyarakat menjadi suatu hal yang penting dalam keberhasilan pembangunan. Mengingat keberhasilan pembangunan hanya dapat terjadi apabila masyarakat tidak hanya menjadi objek pembangunan, namun juga menjadi pembangunan dengan turut berpartisipasi secara aktif dalam program dan kegiatan pembangunan yang dilaksanakan. Bentuk partisipasi masyarakat dapat diwujudkan dalam beraneka macam kegiatan. Dari yang melibatkan pemerintah, komunitas besar hingga secara individual. Partisipasi masyarakarat dalam bentuk penggalangan kesadaran bergotongroyong telah menjadi nilai kebersamaan yang ada dalam masyarakat Indonesia.

Bentuk partisipasi masyarakat secara individu, pada saat ini sangat lebih mudah dan terbuka. Seiring dengan perkembangan jaman yang tidak hanya mengubah pola pikir masyarakat namun juga mengubah gaya hidup. Gaya hidup masyarakat Indonesia pada saat ini sangat dipengaruhi oleh perkembangan teknologi yang demikian pesatnya. Dari mulai cara berinteraksi, berbelanja, hingga menyalurkan sumbangan dalam rangka penggalangan dana masyarakat.

Penggunaan teknologi dalam penggalangan dana juga tidak terlepas dari pengaruh perkembangan teknologi. Menggunakan teknologi dalam kegiatan menerima dan menyebarkan informasi sudah menjadi kebiasaan wajar yang terjadi dalam kehidupan jaman modern. Hal ini dapat terwujud karena perkembangan jaman yang terbantu kemajuan teknologi yang semakin mudah digunakan dan terjangkau, sehingga berbagai informasi yang ada dapat diakses dengan mudah oleh siapa saja. Sehingga kini terbentuk budaya di "era digital" dari komunikasi yang mudah dipercaya dukungan teknologi.

Perkembangan teknologi membawa pada tumbuhnya media-media baru (new media). Keberadaan new media dalam menyajikan informasi cenderung memicu perubahan sosial serta membawa pengaruh pada penetapan pola hidup 
masyarakat. Perubahan sosial tersebut didukung oleh adanya urbanisasi, modernisasi, migrasi, peningkatan tenaga kerja, peningkatan stratifikasi, dan peningkatan mobilitas sosial ${ }^{1}$. Pengaruh media berbeda-beda terhadap setiap individu disebabkan adanya perbedaan pola pikir, perbedaan sifat yang berdampak pada pengambilan sikap, hubungan sosial sehari-hari, dan perbedaan budaya. ${ }^{2}$ New media yang berkembang sangat pesat di masa sekarang ini adalah media sosial. Bahkan media sosial telah menjadi pusat komunikasi antar manusia dalam melakukan berbagai aktivitas, baik dalam bersosialisasi, diseminasi, bisnis, maupun aktivitas sosial.

Media sosial merupakan media untuk interaksi sosial dengan menggunakan teknik penerbitan yang mudah diakses dan terukur. Media sosial merupakan aplikasi online, sarana dan media yang ditujukan untuk memfasilitasi interaksi, kolaborasi dan sharing materi.

Lebih lanjut, media sosial merupakan aplikasi berbasis internet yang dibangun atas dasar ideologis dan teknologi web 2.0, yang dapat menghasilkan penciptaan dan pertukaran dari pengguna konten. Media sosial dapat mengaktifkan komunikasi ke dialog interaktif dengan menggunakan teknologi berbasis web. ${ }^{3}$

Website atau situs diartikan sebagai kumpulan halaman yang menampilkan informasi data teks, data gambar diam atau gerak, data animasi, suara, video dan atau gabungan dari semuanya, baik yang bersifat statis maupun dinamis yang membentuk satu rangkaian bangunan yang saling terkait dimana masing-masing dihubungkan dengan jaringan-jaringan halaman (hyperlink). Bersifat statis apabila isi informasi website tetap, jarang berubah, dan isi informasinya searah hanya dari pemilik website. Bersifat dinamis apabila isi informasi website selalu berubahubah, dan berisi informasi yang bersifat interaktif dua arah dari pemilik serta pengguna website.

Perkembangan jaman juga mempermudah sarana komunikasi yang mampu memberikan kesempatan dan peluang dalam memberikan informasi bagi setiap individu untuk menggunakannya. Sarana komunikasi paling mudah adalah menggunakan media teknologi. Semakin banyak masyarakat menggunakan media tertentu sebagai wadah mendapat keuntungan dan mencapai berbagai tujuan, seperti tempat jual-beli atau mencari informasi. Informasi tentu dapat tersampaikan dengan baik jika semua pihak memiliki kepercayaan dan keyakinan antara satu dengan yang lainnya. Kepercayaan melibatkan kesediaan seseorang untuk bertingkah laku tertentu karena keyakinan bahwa mitranya akan memberikan apa yang ia harapkan dan suatu harapan yang umumnya dimiliki seseorang bahwa kata, janji atau pernyataan orang lain dapat dipercaya. ${ }^{4}$

Kepercayaan adalah keyakinan satu pihak pada reliabilitas, durabilitas, dan integritas pihak lain dalam hubungan dan keyakinan bahwa tindakannya merupakan kepentingan yang paling baik dan akan menghasilkan hasil positif bagi

\footnotetext{
${ }^{1}$ Melvin L.DeFleur (2006). Theorities of Mass Communication, hal. 72

${ }^{2}$ Sri Hastarjo (2011). New Media Teori dan Aplikasi, Karanganyar: Lindu Pustaka

${ }^{3}$ Sisira Neti (2011) Social Media and It's Role in Marketing. International Journal of Enterprise Computing and Business Systems.

${ }^{4}$ Barnes, James G. (2003). Secrets Of Customer Relationship Management, ANDI, Yogyakarta 
pihak yang dipercaya. ${ }^{5}$ Adanya kepercayaan (trust) dalam melakukan kegiatan sosial merupakan wujud dari keyakinan seorang individu atau kelompok dalam mengambil keputusan untuk memilih suatu aktifitas sebagai wadah yang baik untuk kebutuhan hidupnya. Begitu pula dengan new media, keberadaannya menjadi ramai dimanfaatkan untuk menjalankan kegiatan-kegiatan sosial sebagai moda komunikasi, salah satunya untuk menjalankan kampanye sosial yang bertujuan pada dimensi perubahan $\operatorname{sosial}^{6}$ Salah satu perubahan ini diantaranya membawa perubahan pada masyarakat dalam hal ini adalah cara berdonasi dan crowdfunding atau penggalangan dana.

Berasal dari kata 'crowd' yang berarti ramai dan 'funding' yang artinya pendanaan, dengan kata lain crowdfunding sendiri merupakan metode pengumpulan dana secara patungan. Hal ini memungkinkan orang-orang untuk mendapatkan dana tanpa melalui pinjaman sama sekali.

Konsep crowdfunding di Indonesia sebenarnya sudah tidak asing lagi, oleh karena nilai-nilai yang bersifat patungan dan urunan untuk membantu orang lain, baik secara individu maupun yang bersifat massal sudah menjadi sebuah kebiasaan dalam kehidupan masyarakat Indonesia sehari-hari. Crowdfunding memiliki konsep serta nilai-nilai yang sama dengan budaya kita, yaitu nilai saling bergotong royong membantu orang lain dan nilai tersebut yang telah mengakar pada kehidupan bangsa Indonesia.

Konsep crowdfunding dan nilai-nilai kegotong-royongan tersebut melahirkan situs yang berperan sebagai platform crowdfunding di Indonesia, salahsatunya yaitu Kitabisa.com. Kitabisa.com memiliki pandangan dan percaya bahwa Indonesia memiliki banyak potensi dan memiliki banyak orang baik, namun sayang potensi yang ada tersebut terkadang terhalang himpitan rutinitas, sumber daya, dan akses yang terbatas. "Kita bisa" lebih dari sebuah kata-kata. Kitabisa.com menjadi sebuah sarana yang menghubungkan kedua pihak, yaitu orang baik yang memiliki sumber daya dan orang yang memiliki inovasi, inisiatif, dan kreativitas.

Kitabisa.com merupakan penyedia platform crowdfunding terbesar di Indonesia yang berfokus pada isu sosial dan mulai ramai dikenal dengan melakukan aktifitas promosi dengan membuat kegiatan di media sosial. Media sosial menunjang kegiatan crowdfunding yang dilakukan Kitabisa.com termasuk kampanye apa saja yang sedang berjalan dan yang telah sukses di galang dana melalui platform ini. Kitabisa.com menggunakan new media untuk menyebarkan informasi secara luas dan tepat sasaran, serta membangun hubungan dengan masyarakat. Kitabisa.com menawarkan platform baru yang efektif dan efisien bagi masyarakat Indonesia, siapapun bisa menggalang dana dan siapapun bisa berdonasi. Salah satu kampanye yang berhasil membuat Kitabisa.com dikenal hingga manca negara, adalah saat salah satu komunitas rantau Indonesia yang tinggal di Jepang berhasil mengangkat kembali semangat gotong royong dengan menggalang dana untuk membangun masjid di Jepang dan terkumpul dana hingga lebih dari 3 Milyar Rupiah. ${ }^{8}$ Berita ini ramai hingga media televisi, dan

\footnotetext{
5 Peppers, Don and Martha Rogers (2004). Managing Customer Relationships: A Strategic Framework, New Jersey: John Wiley \& Sons, Inc.

${ }^{7}$ https://kitabisa.com/about-us diakses tanggal 18 Oktober 2017

8 https://kitabisa.com/masjidchibajepang diakses tanggal 18 Oktober 2017
} 
Kitabisa.com berhasil dikenal sebagai platform gotong royong terbesar di Indonesia.

Berdasarkan fenomena ini, studi ini memfokuskan pada strategi komunikasi apa yang digunakan dalam membangun kepercayaan khalayak dengan menjadikan Kitabisa.com sebagai alternatif termudah untuk berdonasi online.

\section{TINJAUAN PUSTAKA}

\section{New Media}

Shanon dan Weaver (1949) dalam buku Hafied Cangara mengatakan bahwa komunikasi adalah bentuk interaksi manusia yang saling pengaruh mempengaruhi satu sama lainnya, sengaja atau tidak sengaja. ${ }^{9}$ Komunikasi tidak selalu dilakukan secara tatap muka tetapi dapat pula menggunakan media, baik dalam konteks komunikasi interpersonal atau komunikasi massa, dimana dengan perkembangan teknologi yang telah ada pada saat ini membawa dampak pada tumbuhnya mediamedia baru (new media).

New media membawa perubahan yang sangat signifikan dalam proses perubahan interaksi dan perubahan sosial. Perubahan sosial merupakan proses yang dialami oleh anggota masyarakat serta semua unsur-unsur budaya dan sistem sosial, dimana semua tingkat kehidupan masyarakat secara sukarela atau dipengaruhi oleh unsur-unsur eksternal meninggalkan pola-pola kehidupan, budaya, dan sistem sosial lama yang selanjutnya menyesuaikan diri dan menggunakan pola-pola kehidupan yang baru, budaya yang baru, dan sistem sosial yang baru. ${ }^{10}$

\section{Crowdfunding}

Crowdfunding secara konsep bukan merupakan hal yang baru. Apabila istilah crowdfunding masih terdengar asing mungkin itu terletak pada perkembangan teknologi dan pola pikir yang menggunakan konsep lama namun dengan istilah baru, yakni crowdfunding suatu metode pengumpulan dana secara patungan-konsep lama dengan istilah baru.

Wheat mendefinisikan crowdfunding sebagai sebuah metoda penggalangan dana melalui internet di mana individu meminta bantuan untuk proyeknya melalui website khusus crowdfunding. Crowdfunding merupakan kegiatan mengumpukan dana investasi yang pada umumnya dilakukan melalui situs atau website seperti Twitter, Facebook, Linkedin dan lainnya.

Fokus dari crowdfunding adalah menggalang banyak sumbangan kecil dari pada berupa sumbangan besar dari sebuah lembaga sebagai donor. Crowdfunding berjalan dalam waktu terbatas dari beberapa hari sampai beberapa minggu dan berusaha untuk memenuhi target pendanaan sebelum batas akhir waktu. ${ }^{11}$

Bradford membedakan crowdfunding menjadi lima kategori, yaitu model donasi, model penghargaan (reward), model pra-pembelian, model pinjaman, dan

\footnotetext{
${ }^{9}$ Cangara, Hafied (2014). Pengantar Ilmu Komunikasi.

${ }^{10}$ Burhan Bungin (2013). Sosiologi Komunikasi Teori, Paradigma, dan Diskursus Teknologi Komunikasi di Masyarakat (Jakarta: Kencana Prendan Media Grup)

${ }^{11}$ Rachel E. Wheat (2013). "Raising Money For Scientific Research Through Crowdfunding", Trends in Ecology \& Evolution No. 28, Februari 
model ekuitas. Situs crowdfunding dapat menerapkan satu model atau menerapkan lebih dari satu model. Berikut berbagai macam model situs crowdfunding menurut Bradford: 1) Situs Model Donasi; 2) Situs Model Penghargaan (reward) dan Pra-pembelian; 3) Situs Model Pinjaman; 4) Situs Ekuitas. $^{12}$

\section{METODE PENELITIAN}

Penelitian ini merupakan deskriptif kualitatif dengan pendekatan studi kasus (Case Study). Studi kasus termasuk dalam penelitian analisis deskriptif, yaitu penelitian yang dilakukan terfokus pada suatu kasus tertentu untuk diamati dan dianalisis secara cermat sampai tuntas.

Menurut Robert K. Yin, studi kasus digunakan sebagai salah satu penjelasan komprehensif yang berkaitan dengan berbagai aspek seseorang, suatu kelompok, suatu organisasi, suatu program, atau situasi kemasyarakatan yang diteliti, diupayakan dan ditelaah sedalam mungkin. Studi kasus juga memiliki pengertian berkaitan dengan penelitian yang terperinci tentang seseorang atau suatu unit sosial dalam kurun waktu tertentu. ${ }^{13}$

\section{HASIL DAN PEMBAHASAN}

Kitabisa.com berdiri sejak tahun 2013 yang didirikan oleh Alfatih Timur. Kitabisa.com bertujuan untuk menghidupkan kembali semangat gotong royong yang menjadi kultur dana karakteristik bangsa Indonesia. Pendiri Kitabisa.com ini bercita-cita untuk menggabungkan pergerakan sosial dengan kekuatan teknologi digital dengan menyediakan wadah dan teknologi online bagi individu, komunitas, organisasi maupun perusahaan yang ingin menggalang dana. Dengan membuat halaman donasi online atau yang disebut sebagai halaman campaign, beragam tujuan sosial, personal, kreatif dan lainnya dapat diwujudkan. Melalui Kitabisa.com, para individu juga bisa berdonasi kapan saja secara online ke berbagai kampanye yang disediakan oleh Kitabisa.com sesuai dengan kategori atau organisasi sesuai preferensinya.

Sebagai platform online, Kitabisa.com mengenakan biaya administrasi sebesar 5\% dari total donasi di sebuah kampanye, kecuali kampanye bencana alam dan zakat ( $0 \%$ biaya administrasi). Dengan model ini, Kitabisa.com dapat fokus mengembangkan teknologi dan layanan untuk terus mempermudah kegiatan menggalang dana dan donasi di Indonesia dan dunia.

Yayasan Kitabisa.com tercatat di Kemenkumham dan mendapatkan izin PUB (Penggalangan Uang dan Barang) dari Kementerian Sosial dengan SK Menteri no 478/HUK-PS/2017 dan diaudit oleh Kantor Akuntan Publik dengan hasil Wajar Tanpa Pengecualian. ${ }^{14}$ Berdasarkan data hingga tahun 2016, Kitabisa.com telah berhasil mendanai 6.578 kampanye, menggabungkan 405.783 \#OrangBaik (campaigner dan donatur), dan telah mengumpulkan donasi mencapai lebih dari 100 Milyar Rupiah. Sebagai Founder dan CEO, Alfatih

${ }^{12}$ Bradford, C. Steven (2012). Crowdfunding and the Federal Securities Laws, (Columbus: College of Law, Faculty Publications

${ }^{13}$ Robert K. Yin. (2008). Case Study Research: Desgin and Methods (Applied Social Research Methods). Illinois: Sage Publications, Inc.

${ }^{14}$ https://kitabisa.com/about-us diakses tanggal 18 Oktober 2017 
Timur berhasil menciptakan crowdfunding platform dengan mengisi niche market yang belum terisi sebelumnya oleh platform serupa di Indonesia.

Melalui strategi penggunaan media sosial, Kitabisa.com menyebarkan tagline "Menghubungkan Orang Baik" dan menyebut para pengguna Kitabisa.com sebagai \#OrangBaik. Dengan penggunaan sebutan demikian, Kitabisa.com membangun citra yang kuat dari apa yang ditawarkan. Kini Kitabisa.com telah menjadi top-of-mind dalam platform galang dana, dan juga berhasil menarik banyak inisiatif para anak muda.

Untuk menarik para calon \#OrangBaik, tentu akar utama yang harus diberikan oleh Kitabisa.com adalah kepercayaan dari produknya. Tentu tidak hanya berfokus kepada keunggulan dari jasa Kitabisa.com, namun harus melakukan salah satu upaya dan komunikasi agar brand tersebut tetap exist dipasaran dalam mempertahankan diri dari para imitator dan memiliki ikatan yang kuat dengan audiensnya

Kitabisa.com merupakan platform yang menggalang dana secara online untuk berbagai macam ide-ide perubahan dan kebutuhan. Situs ini terbuka untuk segala bentuk fundraising dan crowdfunding dengan tiga tipe aksi, yaitu:

1. Penggalangan dana untuk diri sendiri, contohnya: personal challenge atau birthday fundraising.

2. Penggalangan dana untuk orang lain, contohnya: untuk teman, kerabat, bahkan orang yang tidak dikenal sekalipun.

3. Penggalangan dana untuk gerakan sosial, contohnya: mendirikan rumah ibadah, mendirikan sekolah, bantuan bencana alam.

Misi yang digalang oleh Kitabisa.com adalah menghubungkan berbagai semangat membangun Indonesia dari berbagai potensi orang baik yang ada di Indonesia melalui semangat gotong royong di era digital. Kitabisa.com menggunakan new media khususnya media sosial sebagai sarana utama penyebaran informasi secara luas, serta menunjang kegiatan crowdfunding melalui online. Penggunaan media sosial oleh Kitabisa.com dilakukan melalui situs jejaring sosial Instagram, Facebook dan Twitter, selain website. Hingga kini, seluruh akun sosial media Kitabisa.com sudah diikuti dengan total seluruhnya lebih dari 150 ribu pengikut. Tentu masing-masing channel memiliki cara berkomunikasi yang berbeda, namun dikemas dengan cerita inspiratif dan storytelling. Selama beberapa tahun berjalan, Kitabisa.com telah banyak melakukan eksperimen mengenai penyampaian komunikasinya dengan tujuan menyampaikan visi dan misi perusahaan dan memiliki motto "Mari bergotong royong membangun Indonesia!". Kitabisa.com mengutamakan pembuatan konten secara maksimal sebagai modal utama dalam menarik minat dan kepercayaan calon konsumen, yang disebut sebagai campaigner dan donatur. Untuk melancarkan kegiatan kampanye sosial di media sosial, Kitabisa.com melakukan pengenalan donasi online melalui media sosial. Tujuan pengenalan kampanye ini kepada masyarakat agar masyarakat bertransformasi dari donasi offline ke donasi online.

Hal yang paling penting dalam keberhasilan proses komunikasi adalah pesan. Proses komunikasi dapat dikatakan berhasil apabila pesan dapat diterima oleh audiens sesuai dengan tujuan komunikator. Oleh karena itu, penyusunan pesan menjadi hal yang penting mengingat pesan ini nantinya harus mudah dipahami dan diterima oleh khalayak. 
Mengacu pada Young (2012) dalam Wheat (2013) langkah-langkah dalam melakukan crowdfunding, yaitu membuat proyek yang menarik, membuat sebuah video promosi, target pendanaan yang tepat, dan durasi promo yang tepat. Dari sisi format, format yang digunakan berfokus pada format video. Hal ini dikarenakan format video lebih menarik bagi masyarakat untuk menyimak penjelasan mengenai kampanye sosial sehingga memberikan peluang besar bagi calon donatur untuk berdonasi. Format video juga dapat di putar berulang kali sehingga format ini lebih menarik apabila dibandingkan dengan format foto. ${ }^{15}$

Dari sisi tipe konten, konten yang berkualitas akan membuat suatu website selalu diingat oleh pengikutnya. Kitabisa.com menggunakan beberapa tipe konten yang diunggah pada media sosial dan menjadi acuan seperti success story, momentum, cerita komunitas, dan light content. Tipe konten tersebut menjadikan Kitabisa.com populer di kalangan masyarakat berkat kontennya yang berbobot, memberikan isi pesan yang menarik, selalu menebarkan kebaikan dan memudahkan masyarakat untuk menggalang dana dan berdonasi secara online. Success story menjadi konten yang paling menarik perhatian masyarakat, khususnya bagi para calon campaigner dan donatur. Konten success story cenderung dapat memberikan motivasi dan optimisme bahwa masih banyak kebaikan yang terjadi di sekitar kita, dan masyarakat masih bisa ikut serta dalam memberikan harapan dan kebahagiaan untuk orang lain.

Dalam menyampaikan tujuan untuk menarik campaigner, Kitabisa.com menggunakan strategi dengan menggunakan storytelling. Strategi ini dimaksudkan untuk menambah keyakinan campaigner ataupun donatur. Melalui media sosial ataupun website kita menunjukkan bahwa melalui Kitabisa.com, akan lebih mudah berdonasi untuk membantu orang lain. Kemudian kita update success story dari yang terbantu.

Dengan menggunakan platform yang sudah ada, konsistensi dan figur terkenal dapat memperkuat informasi yang ingin disampaikan. Selain membuat konten yang bagus dan berkualitas, platform digital tidak membatasi jumlah komunikasi yang terjalin antara komunikator dan komunikan. Bahkan siapapun bisa menjadi komunikator jika audiens atau konsumen yang dituju sudah sesuai dan tepat.

Apa yang dilakukan oleh Kitabisa.com menjadi suatu bahwa kekuatan komunikasi digital yang disampaikan melalui media online menjadi strategi yang efektif untuk menumbuhkan partisipasi khalayak dalam penggalangan dana. Bentuk strategi komunikasi semacam ini pada hakekatnya dekat dengan apa yang disebut dengan digital marketing communication.

Digital marketing communication adalah bentuk komunikasi pemasaran langsung atau tidak langsung yang digunakan untuk membangun kesadaran, pengakuan, ingat, dan tindakan untuk merek, bisnis, produk, orang, atau badan lain dan dilakukan dengan menggunakan alat-alat dari Web sosial, seperti sebagai berbagi blogging, mikrobloging, jejaring sosial, bookmark sosial, dan konten. Digital marketing mencakup taktik tertentu seperti berbagi kupon atau mengumumkan penjualan di Facebook atau Twitter, atau bisa mencakup lebih luas membangun merek inisiatif seperti berkomunikasi dengan orang-orang atau

\footnotetext{
15 Rachel E. Wheat (2013). "Raising Money For Scientific Research Through Crowdfunding”, Trends in Ecology \& Evolution
} 
menciptakan konten yang menarik dalam sebuah video yang diunggah ke Youtube. Selain itu, pemasaran media sosial menawarkan kesempatan besar untuk pengusaha, usaha kecil, perusahaan menengah, dan perusahaan besar untuk membangun merek mereka dan bisnis mereka.

Menurut Gunelius, tujuan paling umum dari pemasaran media sosial:

a. Membangun hubungan: manfaat utama dari pemasaran media sosial adalah kemampuan untuk membangun hubungan dengan konsumen secara aktif.

b. Membangun merek: percakapan melalui media sosial menyajikan cara sempurna untuk meningkatkan brand awareness, meningkatkan pengenalan dan ingatan akan merek dan meningkatkan loyalitas merek.

c. Publisitas: pemasaran melalui media sosial menyediakan outlet di mana perusahaan dapat berbagi informasi penting dan memodifikasi persepsi negatif.

d. Promosi: melalui pemasaran media sosial, memberikan diskon eksklusif dan peluang untuk audiens untuk membuat orang-orang merasa dihargai dan khusus, serta untuk memenuhi tujuan jangka pendek.

e. Riset pasar: menggunakan alat-alat dari web sosial untuk belajar tentang pelanggan, membuat profil demografi dan perilaku pelanggan, belajar tentang keinginan dan kebutuhan konsumen, serta belajar tentang pesaing. ${ }^{16}$

Lebih lanjut, bentuk partisipasi masyarakat dalam pengagalang dana secara online ini mengarah pada perilaku konsumen seperti dalam teori AISAS. AISAS adalah suatu model perilaku konsumen online yang dikembangkan oleh Dentsu Group yang merupakan satu perusahaan iklan terbesar di dunia yang didirikan di Jepang. Model AISAS ini dinilai dapat menjelaskan perilaku konsumen secara lebih akurat dari model-model sebelumnya. AISAS sendiri terbentuk dari Attention (perhatian), Interest (ketertarikan), Search (pencarian), Action (aksi), dan Share (berbagi). Perubahan pola perilaku ini didorong oleh perkembangan pesat teknologi internet sehingga menciptakan era digital atau online. ${ }^{17}$

Pada intinya, pertama, pendekatan IMC Dentsu disusun berdasarkan studi mendalam terhadap ide-ide yang muncul dari konsumen. Kedua, tidak hanya fokus pada jangkauan dan frekuensi penyampaian pesan kepada target audience (kuantitas) tapi juga dengan melibatkan konsumen (kualitas). Ketiga, strategi komunikasi diarahkan pada penciptaan skenario yang mengarahkan konsumen untuk secara sukarela mencari informasi mengenai produk, membeli produk, dan kemudian menyebarkan positive word-of-mouth ke konsumen lain. Keempat, komunikasi harus melihat titik koneksi konsumen dengan merk membangun persamaan persepsi dengan orang, lalu menggerakkannya sesuai keinginan kita. ${ }^{18}$

Melalui strategi komunikasi yang dibangun oleh Kitabisa.com, khalayak dibuat interested dan give attention, untuk kemudian search atas pesan yang disampaikan dan pada akhirnya melakukan action dan share kepada khalayak lainnya. Strategi ini secara nyata sangat efektif dalam mendorong partisipasi khalayak dalam penggalangan dana. Sehingga apa yang menjadi tujuan dari pesan yang disampaikan oleh Kitabisa.com benar-benar dapat terealisasi dan terwujud,

\footnotetext{
${ }^{16}$ Gunelius, Susan. 2011. 30-Minute Social Media Marketing. United States: McGraw- Hill Compani es, Hal 10

${ }^{17}$ Sugiyama, Kotaro and Tim Andree. 2011. The Dentsu Way. McGraw Hill: New York City

18 ibid 
yaitu untuk dapat bersama-sama bergotong royong membantu sesama melalui penggalangan dana.

\section{KESIMPULAN DAN SARAN}

\section{Kesimpulan}

Untuk mendorong partisipasi khalayak agar bertransformasi dari donasi offline ke donasi online, Kitabisa.com mempunyai strategi komunikasi melalui penggunaan media sosial. Strategi tersebut adalah dengan cara mengunggah konten yang berisi storytelling dan format video dalam setiap kampanye yang akan dilakukannya di media sosial yang digunakan. Dengan format video, rekaman dapat diputar berulang-ulang kali sehingga menarik perhatian masyarakat yang ingin berdonasi di kampanye sosial tersebut dibandingkan format foto. Kampanye media sosial yang dilakukan oleh Kitabisa.com selama ini menjangkau banyak khalayak yang memiliki ketertarikan yang sama dengan tujuan Kitabisa.com.

Kitabisa.com selalu memberikan update campaign/laporan perkembangan dari setiap aktivitas sosial yang telah dilakukannya dan bukti berupa foto-foto yang ditampilkan dalam website secara transparan. Penyebaran konten secara konsisten dan maintenance yang terus menerus dilakukan Kitabisa.com dalam media sosial dilakukan untuk menjaga kualitas campaign yang perlu didanai dan meningkatkan kepercayaan khalayak.

Pengalangan dana kampanye sosial dilakukan Kitabisa.com dengan para calon donatur melalui media digital. Penyebaran kampanye sosial yang dilakukan oleh penggalang dana lewat media sosial adalah sebuah upaya untuk menyampaikan pesan pada calon donator maupun donatur untuk ikut dan terus berpartisipasi berdonasi. Kitabisa.com sebagai penggalang dana membuka diri dengan menyebarkan kampanye sosial, sehingga penggalang dana mendapatkan respon dari para donatur dan menciptakan engagement dengan upaya menarik donasi dari para calon donatur.

\section{DAFTAR PUSTAKA}

Andrew F. Wood dan Matthew J. Smith (2005). Online Communication: Linking Technology, Identity and Culture. (New Jersey: Lawrence Erlbaum Associates, Inc)

Bradford, C. Steven (2012). Crowdfunding and the Federal Securities Laws, (Columbus: College of Law, Faculty Publications

Cangara, (2012) Hafied.- Pengantar Ilmu

Komunikasi Jakarta: RajaGrafindo Persada

Daft, R.L., dan Lengel, R.H. (1984). Information richness: A new approach to managerial information processing and organizational design. Greenwich, CT: JAI Press.

Erna, Ferrinadewi (2008) Pengaruh Threat Emotion Konsumen Dan Brand Trust Pada Keputusan Pembelian Produk Susu Anlene Di Surabaya. Jurnal. Universitas Widya Kartika.

Griffin, Emory A. (2003). A First Look at Communication Theory. Singapore: McGraw-Hill. 
Gunelius, Susan. 2011. 30-Minute Social Media Marketing. United States: McGraw- Hill Companies,

Hastarjo, Sri (2011). New Media Teori dan Aplikasi, Karanganyar: Lindu Pustaka

Kitabisa.com (2014). Perkembangan Crowdfunding Dahulu Hingga Kini, diakses pada tanggal 15 Oktober erkembangan-crowdfunding-2017, https://blog.kitabisa.com/2015/03/pdahulu-hingga-kini/

Neti, Sisira (2011) Social Media and It's Role in Marketing. International Journal of Enterprise Computing and Business Systems.

Peppers, Don and Martha Rogers (2004). Managing Customer Relationships: A Strategic Framework, New

Rachel E. Wheat (2013). "Raising Money For Scientific Research Through Crowdfunding”, Trends in Ecology \& Evolution No. 28

Richter A. \& Koch M. (2007). Social Software- Status quo und Zukunft. Technischer Bericht. Nr. 2007-01, Fakultat fur Informatik. Universitat der Bundeswehr Munchen

Straubhaar, Joseph \& La Rose, Robert. (2004) Media Nocalonw: Communications Media in the Information Age. Wadsworth

Sugiyama, Kotaro and Tim Andree. 2011. The Dentsu Way. McGraw Hill: New York City

Thurlow, Crispin, Laura Lengel and Alice Tomic (2004). Computer Mediated Communication: Social Interaction and The Internet. (California: SAGE Publications)

Uchjana, Onong. (2003). Ilmu, Teori, dan Filsafat Komunikasi, PT. Citra Aditya Bakti, Bandung

Werbin, Kenneth C. (2015) The Social Media Contract: On the Paradoxes of Property in This Digital Land Journal of Canadian Studies; Toronto Vol. 46, The Social Media Contract: On the Paradoxes of Digital Digital Property in This Digital Land

Yuhefizar (2013). Cara Mudah \& Murah Membangun \& Mengelola Website. Jakarta: Graha Ilmu. 